\title{
Endoscopic retrieval of a proximally migrated biliary stent within the gallbladder lumen
}

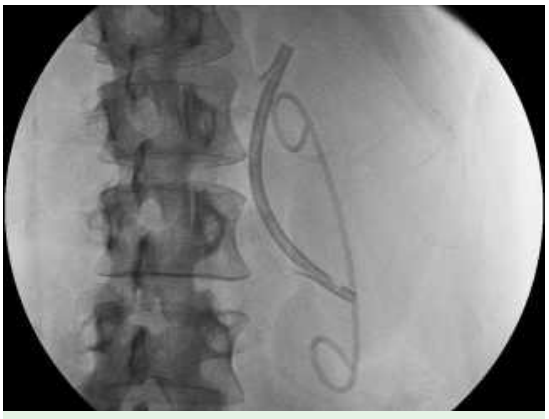

Fig. 1 A scout film was taken because the distal end of the pigtail stent was not visible endoscopically at the papillary orifice but the stent was seen within the biliary tree, and this showed the proximally migrated stent.

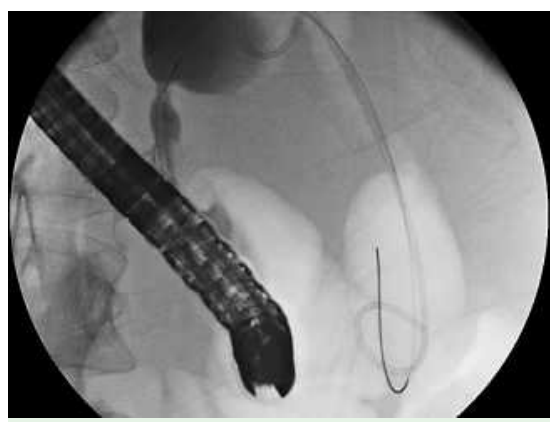

Fig. 2 A guide wire was passed into the gallbladder lumen.
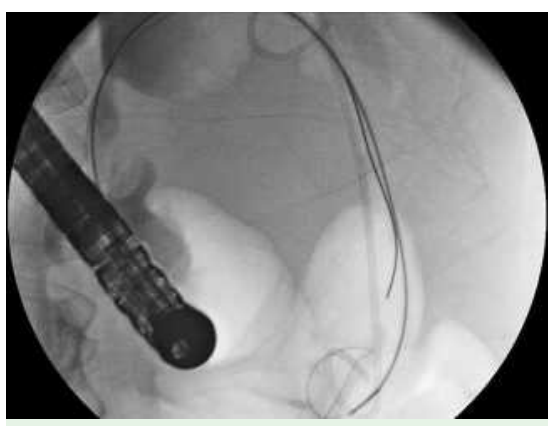

Fig. 3 A medium-sized snare was then passed over the guide wire into the gallbladder.

Endoscopic techniques for retrieval of migrated biliary endoprostheses include stent cannulation and subsequent balloon retrieval, balloon placement parallel to the stent with traction retrieval, and the use of a wire basket, snare, Soehendra stent retriever, or rat-tooth forceps [1 - 3].

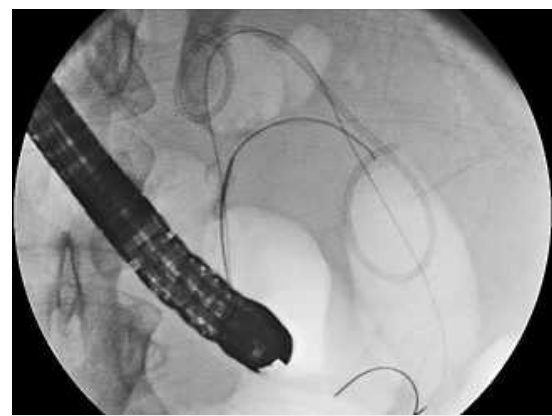

Fig. 4 The snare was opened and used to capture and eventually retrieve the stent under fluoroscopic guidance.

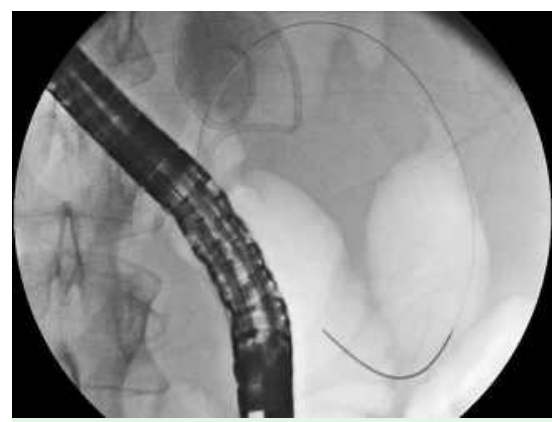

Fig. 5 The stent was withdrawn into the distal common bile duct.

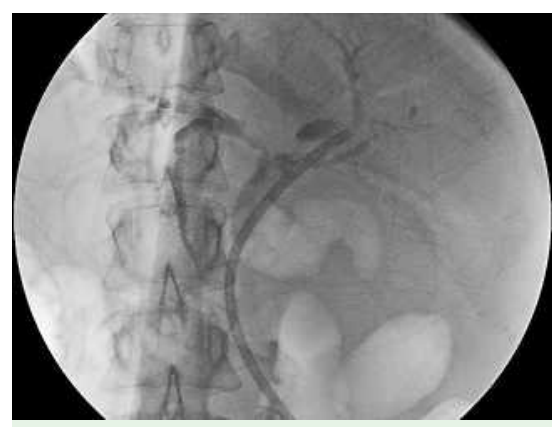

Fig. 6 A 10-Fr, 9-cm stent was placed into the right intrahepatic system after tissue had been obtained for analysis because the patient still had a dominant distal bile duct stricture.

The technique chosen depends on the extent of proximal stent migration, the presence of ductal dilatation or biliary stricture, and the endoscopist's experience. This report describes the retrieval of a proximally migrated biliary stent located within the gallbladder lumen.
A 40-year-old woman with primary sclerosing cholangitis underwent stent placement during a procedure to evaluate a dominant stricture. She subsequently presented with cholangitis, and the previously placed 7-Fr double-pigtail biliary stent was found to have migrated proximally into the gallbladder. She was referred to our center after a failed stent retrieval procedure, when a second straight stent was placed in order to provide drainage ( $\bullet$ Fig. 1 ).

After the straight stent was removed, a 0.035 -inch guide wire was fed through the cystic duct and coiled within the gallbladder ( $\bullet$ Fig. 2). A medium-sized snare was then placed over the guide wire into the gallbladder, and this allowed capture and eventual retrieval of the stent under fluoroscopic guidance ( $\bullet$ Fig. 3-5). Subsequent cholangiography once again showed a dominant common bile duct stricture. After brush cytology and intraductal biopsies were obtained, a 10-Fr, 9$\mathrm{cm}$ straight stent was then placed within the right intrahepatic system without further complications ( $\bullet$ Fig. 6 ).

In this report we have described a method for retrieving stents that have migrated into the gallbladder, a problem that could could become more common in future, given the growing tendency to use stents to manage gallbladder disease $[4,5]$. Notably, the endoscopist must be careful to avoid cystic duct injury during access attempts during planned stent placement procedures.

\section{Endoscopy_UCTN_Code_TTT_1AR_2AZ}

F. C. Gleeson, B. T. Petersen, M. J. Levy

Division of Gastroenterology and Hepatology, Mayo Clinic Foundation, Rochester, Minnesota, USA 


\section{References}

1 Tarnasky PR, Morris J, Hawes RH et al. Snare beside-a-wire biliary stent exchange: a method that maintains access across biliary strictures. Gastrointest Endosc 1996; 44: $185-187$

2 Tarnasky PR, Cotton PB, Baillie J et al. Proximal migration of biliary stents: attempted endoscopic retrieval in forty-one patients. Gastrointest Endosc 1995; 42: 513-520

3 Chaurasia OP, Rauws EA, Fockens P, Huibregtse $K$. Endoscopic techniques for retrieval of proximally migrated biliary stents: the Amsterdam experience. Gastrointest Endosc 1999; 50: 780 - 785
4 Conway JD, Russo MW, Shrestha R. Endoscopic stent insertion into the gallbladder for symptomatic gallbladder disease in patients with end-stage liver disease. Gastrointest Endosc 2005; 61: 32 - 36

5 Schlenker C, Trotter JF, Shah RJ et al. Endoscopic gallbladder stent placement for treatment of symptomatic cholelithiasis in patients with end-stage liver disease. Am J Gastroenterol 2006; 101: 278-283
Bibliography

DOI $10.1055 / s-2007-966869$

Endoscopy 2008; 40: E3-E4

(c) Georg Thieme Verlag KG Stuttgart · New York . ISSN 0013-726X

\section{Corresponding author}

\section{J. Levy, MD}

Division of Gastroenterology and Hepatology Mayo Clinic College of Medicine 200 First Street SW, Charlton 8

Rochester

Minnesota 55905

USA

Fax: +1-507-266-3939

levy.michael@mayo.edu 